\title{
Experimental Evaluation of the Thermal Performance of a Water Shield for a Surface Power Reactor
}

\author{
J Boise Pearson ${ }^{1}$, Eric T. Stewart ${ }^{1}$, Robert S. Reid ${ }^{2}$ \\ ${ }^{I}$ NASA Marshall Space Flight Center, Huntsville, AL 35812 USA \\ ${ }^{2}$ Los Alamos National Laboratory, Los Alamos, NM 87544 USA \\ 256-961-0078, j.boise.pearson@nasa.gov
}

\begin{abstract}
A water based shielding system is being investigated for use on initial lunar surface power systems. The use of water may lower overall cost (as compared to development cost for other materials) and simplify operations in the setup and handling. The thermal hydraulic performance of the shield is of significant interest. The mechanism for transferring heat through the shield is natural convection. Natural convection in a representative lunar surface reactor shield design is evaluated at various power levels in the Water Shield Testbed (WST) at the NASA Marshall Space Flight Center. The experimental data from the WST is used to anchor a CFD model. Performance of a water shield on the lunar surface is then predicted by CFD models anchored to test data.
\end{abstract}

Keywords: Fission, Reactor, Structural, Shield, Material

PACS: $28.41 \mathrm{Qb}, 28.50-\mathrm{k}, 29.40-\mathrm{Vj}$

\section{INTRODUCTION}

As part of the Vision for Space Exploration the end of the next decade will bring man back to the surface of the moon. One of the most critical issues for the establishment of human presence on the moon will be the availability of compact power sources (Angelo and Buden, 1985). The establishment of man on the moon will require power from greater than 10's of kWt's in follow on years. Nuclear reactors are well suited to meet the needs for power generation on the lunar or Martian surface.

Shielding is a key component of any surface power reactor system. Several competing concepts exist for lightweight, safe, robust shielding systems such as a water shield, lithium hydride ( $\mathrm{LiH})$, and boron carbide. Water offers potential advantages, including reduced cost, reduced technical risk, and reduced mass. Water has not typically been considered for space reactor applications because of temperature requirements associated with thermoelectric and thermionic power conversion, and the need for gravity to remove the potential for radiation streaming paths. Experimental demonstration of these concepts, specifically targeted on key technical challenges or questions is critical to accurate evaluation of their relative merits. LiH shields can be expensive to fabricate, and need to prove adequate radiation tolerance under potential operating conditions. Water shields need to be shown to have adequate natural convection to prevent bubble formation or unacceptably high-temperature regions while operating in conjunction with a high temperature reactor coupled to a modern (e.g. Stirling, Brayton, or organic Rankine) power conversion subsystem. The water shield concept relies on predictions of passive circulation of the shield water by natural convection to adequately cool the shield. These predictions needs to be experimentally evaluated, especially for shields with complex geometries. NASA Marshall Space Flight Center (MSFC) has developed the experience and facilities necessary to do this evaluation in the Early Flight Fission - Test Facility (EFF-TF).

The EFF-TF, was established to provide a capability at MSFC for performing hardware directed activities relevant to multiple nuclear power reactor concepts using non-nuclear test methodology. EFF-TF capability includes fabrication and testing, at both the module/component level, and near prototypic hardware configurations allowing for realistic thermal hydraulic evaluations of systems. To date the EFF-TF has examined heat pipe reactor systems 
(Bragg-Sitton, 2005), gas cooled reactor systems (Godfroy et al., 2004), and liquid metal reactor systems. The methods and experience of this successful team are exactly what is required to experimentally evaluate the natural convection in the water shield.

The objectives of the work in this paper are to experimentally and analytically demonstrate the thermal performance of a prototypic water shield for a lunar surface reactor. The experiment is done in earth gravity with full-scale prototypic geometry and heat load, and a CFD model is anchored to this experimental data. The CFD model is then used to predict thermal performance in lunar gravity.

\section{EXPERIMENT DESCRIPTION}

This experiment was performed in the Water Shield Testbed (WST) at the NASA Marshall Space Flight Center. The geometry and power requirements for the WST were based on a SNAP derivative reactor design from Los Alamos National Laboratory (Dixon et al., 2006). Figure 1 is a conceptual design of this reactor system.

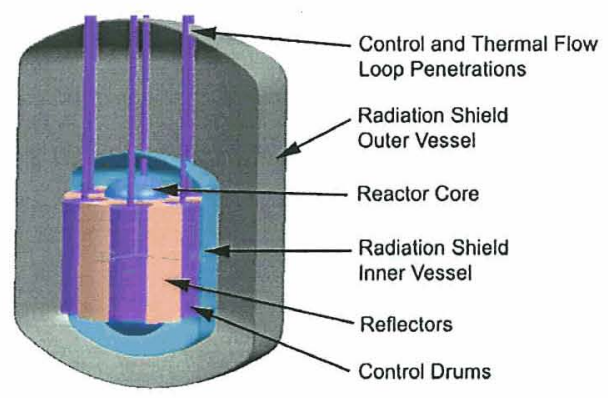

FIGURE 1. Simplified Conceptual Design of a SNAP Derivative Reactor and Water Shield.

The WST consists of an outer tank to simulate the shield's outer vessel, and a core simulator that simulates the reactor vessel and everything inside it (core, reflector, control drums, coolant manifolds, etc.). The outer tank is a stainless steel tank approximately $90 \mathrm{~cm}$ in diameter and $1.5 \mathrm{~m}$ tall. The core simulator is made from $.64 \mathrm{~cm}$ aluminum with a $61 \mathrm{~cm}$ diameter and $76 \mathrm{~cm}$ height, with a $7.5 \mathrm{~cm}$ diameter pipe representing vertical penetrations of the shield.
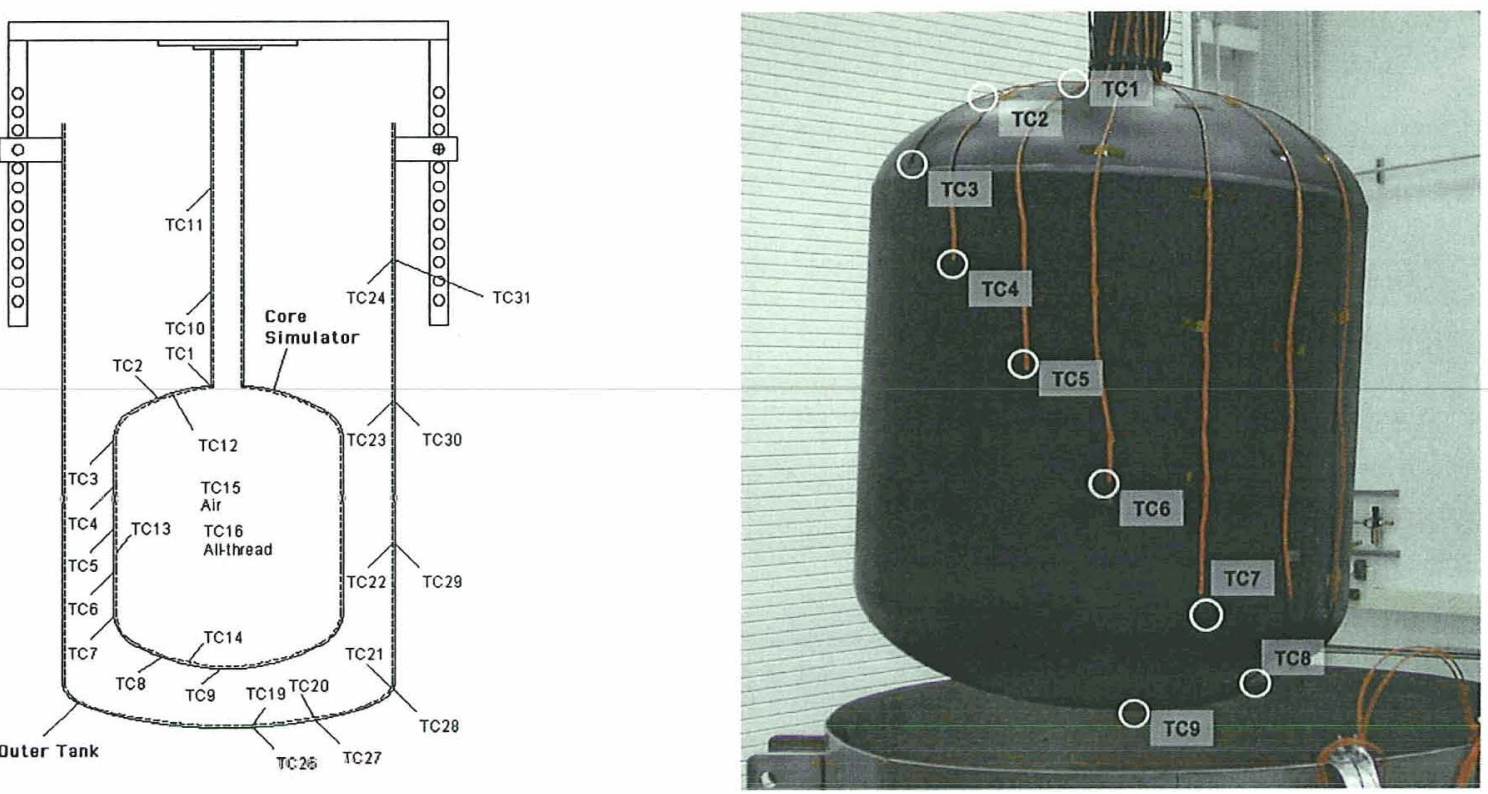
FIGURE 2. Shield Test Vessel.Layout of Water Shield Testbed with Thermocouple Placement and Numbering.

Figure 2 shows the placement of these two pieces, and the thermocouple locations for each. Note that the thermocouples are staggered azimuthally on the core simulator in an attempt to place each thermocouple in undisturbed flow. Thermocouples on the outer tank are similarly staggered. A $5 \mathrm{~cm}$ thick styrofoam lid is placed at the top of the outer tank to prevent evaporative cooling losses, but does not pressurize the tank. A band heater is placed on the core simulator pipe, just above the lid to act as a guard heater, forcing all the heat to flow through the outer tank walls.

Heaters are placed inside the core simulator to provide the internal boundary condition. The heaters are controlled to provide a constant power setting. Heaters are separated in three zones; top dome, barrel, and bottom dome. Total power for this test was $2 \mathrm{~kW}$, with $500 \mathrm{~W}$ in each dome and $1000 \mathrm{~W}$ in the barrel section. Figure 3 shows the heater placement in the core simulator. The outer boundary condition for the test was natural convection in still air.

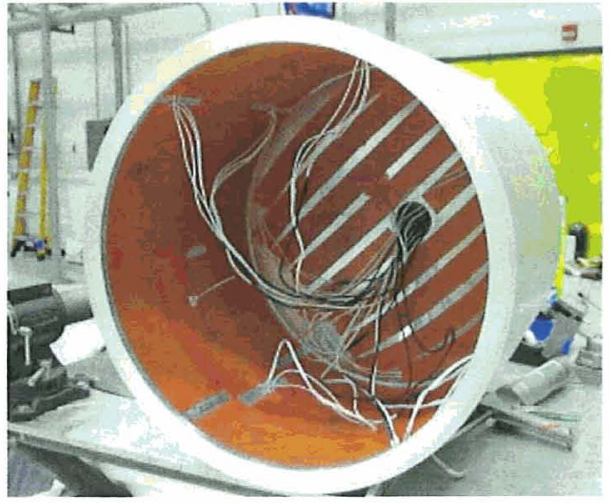

(a) Barrel and Top Dome.

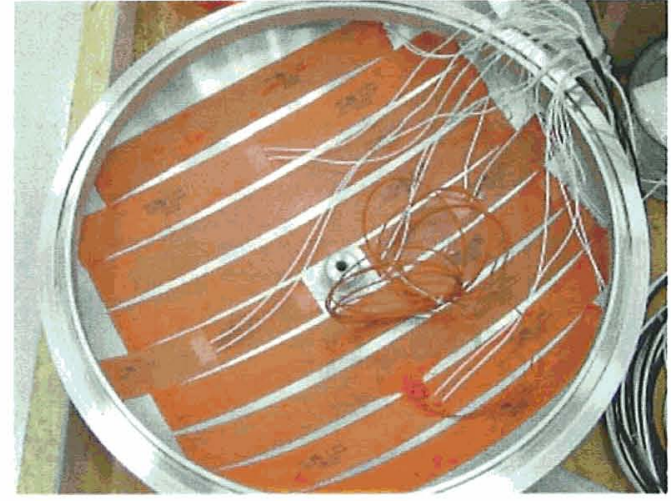

(b) Bottom Dome.

FIGURE 3. Heater Placement in Core Simulator.

\section{EXPERIMENTAL RESULTS}

The experiment was run by setting the heater power to $2 \mathrm{~kW}$, and allowing the experiment to come to steady state thermal conditions. Figure 4 illustrates the results of the experiment. Note that the experiment was started from steady state conditions with $1 \mathrm{~kW}$ of heater power, not from thermal equilibrium with room temperature. A computer crash at roughly 32 hours caused a short loss of power. The steady state results are used to anchor the CFD model in the $1-\mathrm{g}$ case.

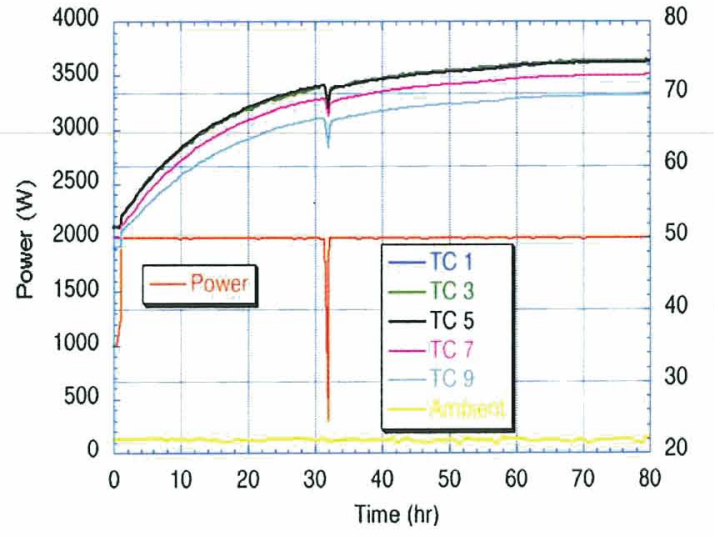

(a) Core Simulator.

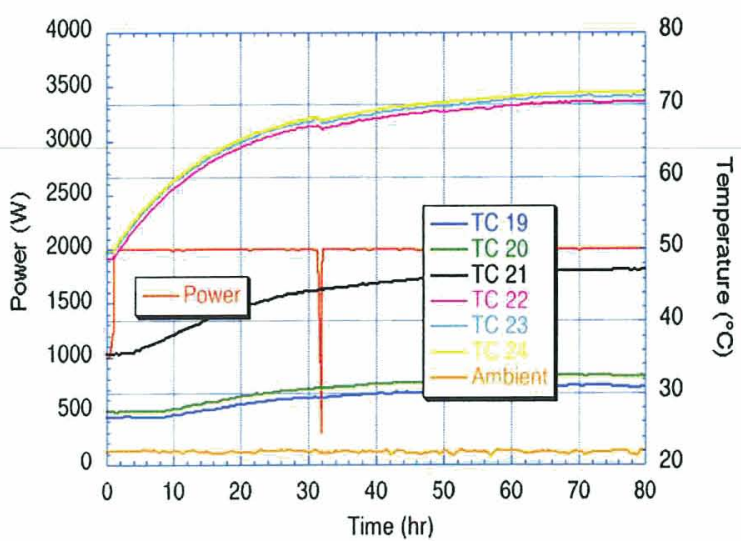

(b) Outer Tank. 
FIGURE 4. Experimentally Measured Transient Behavior of Water Shield.

Test bed data consistently shows small time-correlated cooling spikes on thermocouples 3 and 4 (Figure 5). Data from thermocouple 6 is included to show 'normal' steady-state behavior. These two thermocouples are located at and just below the top of the barrel section of the core simulator. A likely explanation is the repeated formation and shedding of vortices around the transition from the barrel to dome section.

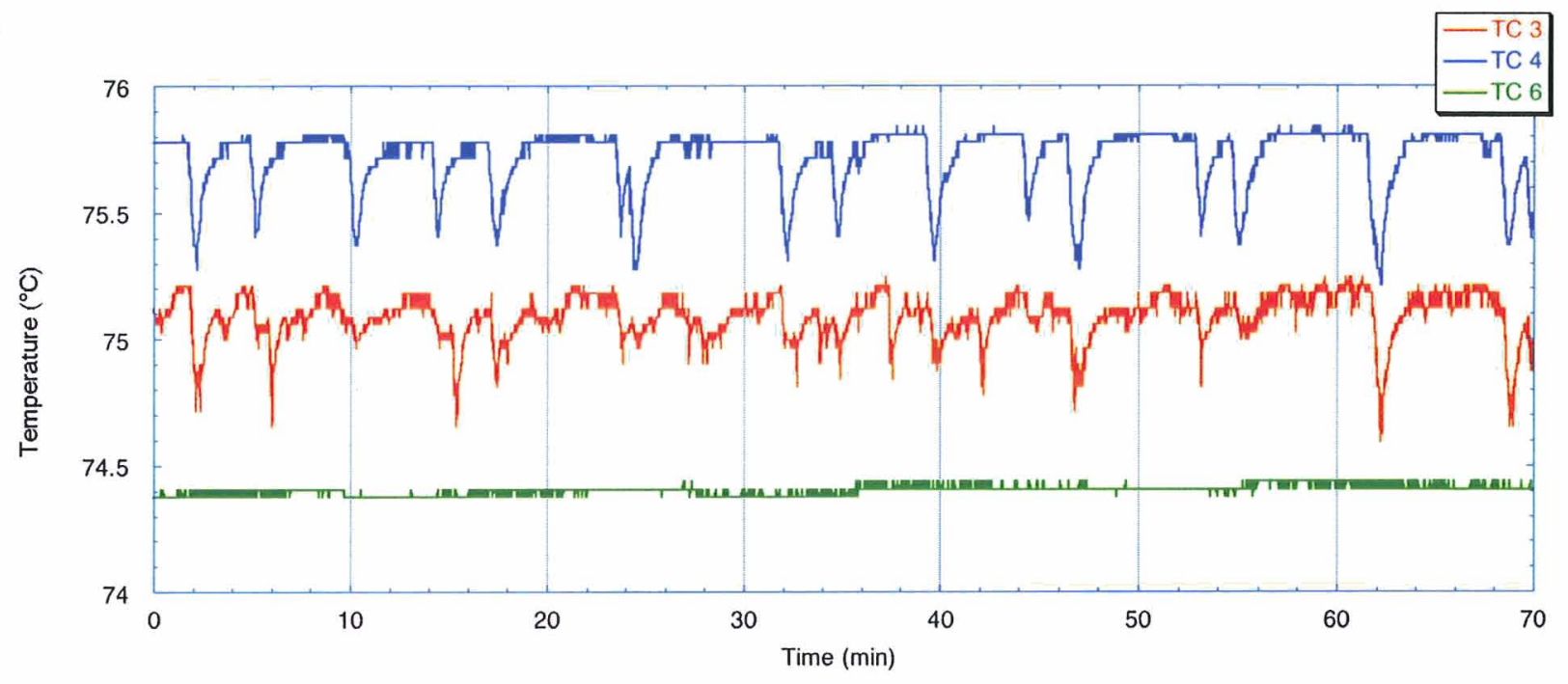

FIGURE 5. Evidence of Periodic Oscillations in Flow.

\begin{abstract}
ANALYSIS
Computational fluid dynamic (CFD) analyses were performed of the water shield test set-up. The long term objective is for CFD to facilitate the design of water shields on the lunar surface where prototype testing becomes more difficult due to the reduced gravitational environment. In the more near term, the current analyses represent the first steps toward achieving this long term goal.
\end{abstract}

\title{
Computational Fluid Dynamics Code
}

Software developed internally at Marshall Space Flight Center (Stewart, 2001) was used to perform pre-processing and CFD. Post-processing was performed with Tecplot (Tecplot, 1999). Calculations were performed on an HP Compaq nc4010 laptop. The governing equations, in axisymmetric non-dimensional form are:

$$
\begin{gathered}
\frac{\partial u_{r}^{*}}{\partial r^{*}}+\frac{u_{r}^{*}}{r^{*}}+\frac{\partial u_{z}^{*}}{\partial z^{*}}=0 \\
\frac{\partial u_{r}^{*}}{\partial t^{*}}+u_{r}^{*} \frac{\partial u_{r}^{*}}{\partial r^{*}}+u_{z}^{*} \frac{\partial u_{r}^{*}}{\partial z^{*}}=-\frac{\partial P^{*}}{\partial r^{*}}+v^{*}\left(\frac{\partial}{\partial r^{*}}\left(\frac{1}{r^{*}} \frac{\partial}{\partial r^{*}}\left(r^{*} u_{r}^{*}\right)\right)+\frac{\partial^{2} u_{r}^{*}}{\partial z^{* 2}}\right) \\
\frac{\partial u_{z}^{*}}{\partial t^{*}}+u_{r}^{*} \frac{\partial u_{z}^{*}}{\partial r^{*}}+u_{z}^{*} \frac{\partial u_{z}^{*}}{\partial z^{*}}=-\frac{\partial P^{*}}{\partial z^{*}}+v^{*}\left(\frac{1}{r^{*}} \frac{\partial}{\partial r^{*}}\left(r^{*} \frac{\partial u_{z}^{*}}{\partial r^{*}}\right)+\frac{\partial^{2} u_{z}^{*}}{\partial z^{* 2}}\right)-T^{*} G r \\
\frac{\partial T^{*}}{\partial t^{*}}+u_{r}^{*} \frac{\partial T^{*}}{\partial r^{*}}+u_{z}^{*} \frac{\partial T^{*}}{\partial z^{*}}=\alpha^{*}\left(\frac{1}{r^{*}} \frac{\partial}{\partial r^{*}}\left(r^{*} \frac{\partial T^{*}}{\partial r^{*}}\right)+\frac{\partial^{2} T^{*}}{\partial z^{* 2}}\right)
\end{gathered}
$$


where

$$
\begin{aligned}
& t^{*}=\frac{t}{\Delta t}, r^{*}=\frac{r}{\Delta s}, z^{*}=\frac{z}{\Delta s}, u_{r}^{*}=\frac{u_{r} \Delta t}{\Delta s}, u_{z}^{*}=\frac{u_{z} \Delta t}{\Delta s}, \mathrm{P}^{*}=\frac{P \Delta t^{2}}{\rho_{r e f} \Delta s^{2}}, \\
& \mathrm{~T}^{*}=\frac{T-T_{\min }}{T_{\max }-T_{\min }}, v^{*}=\frac{\left(v+v_{t}\right) \Delta t}{\Delta s^{2}}, \alpha^{*}=\frac{\left(\alpha+\alpha_{t}\right) \Delta t}{\Delta s^{2}}, \mathrm{Gr}=\frac{\beta \Delta t^{2}}{\Delta s}\left(T_{\max }-T_{\min }\right) g,
\end{aligned}
$$

The Baldwin-Lomax turbulence model (Baldwin, Lomax, 1978) is used to determine $v_{t}$ and $\alpha_{t}$. An explicit, finite difference numerical method is applied to approximate the governing equations along with pseudo compressibility to enforce incompressibility. Figure 6 illustrates the computational geometry and the applied boundary conditions at each boundary. The computational geometry appears to be shaded but is actually a picture of the computational grid and is indicative of the dense grid spacing. The grid contains 23,368 points. For boundaries 2 and 5 the symbol $n$ is used for the distance normal to the surface. The other surfaces lie on constant $\mathrm{r}$ or $\mathrm{z}$ lines and the appropriate $\mathrm{r}$ or $\mathrm{z}$ derivatives are used there.

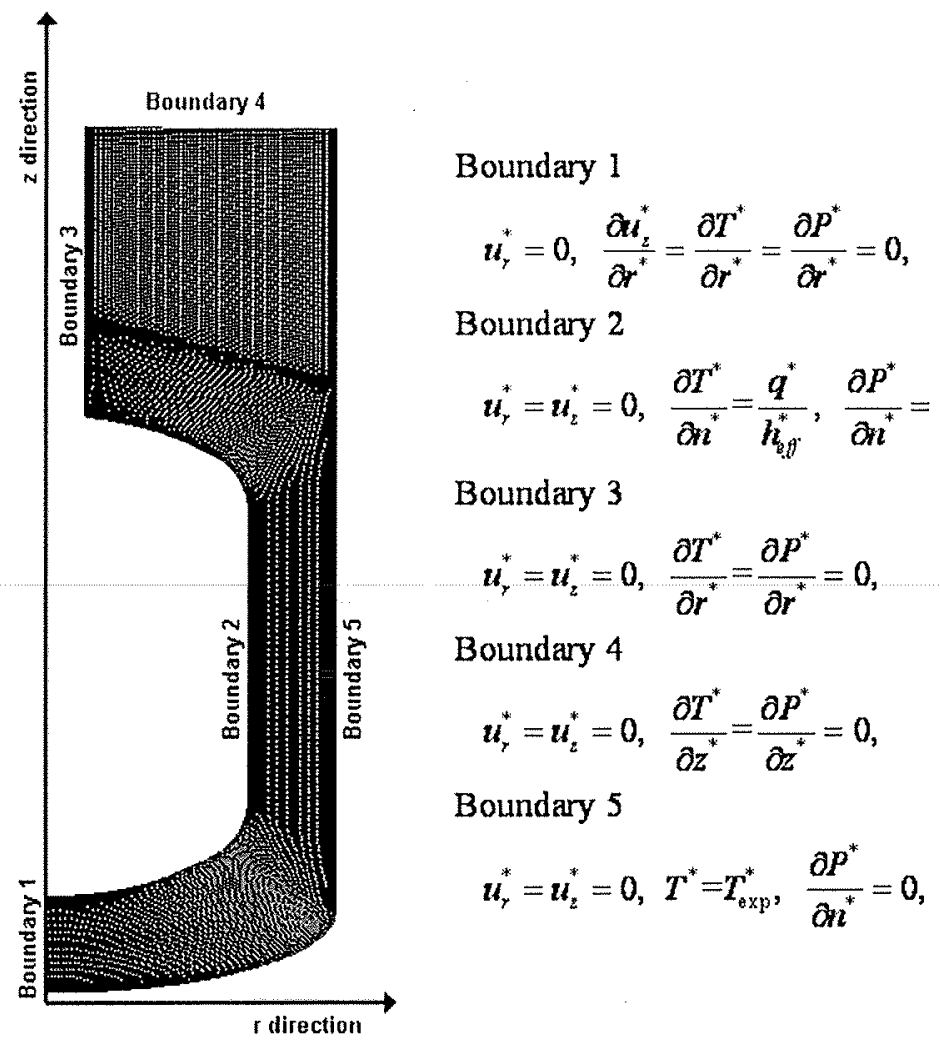

FIGURE 6. Computational Geometry and Boundary Conditions

\section{CFD Model Anchored to 1-g Test Data}

The experimental data used to anchor the CFD model (i.e., determine $h_{\text {eff }}$ and $T_{\text {exp }}$ ) are from the experimental case where the total heat input was $2000 \mathrm{~W}$ across the reactor simulator surface (boundary 2) and the bottom of the reactor simulator was $15 \mathrm{~cm}$ from the bottom of the outer tank. Two steps were taken to anchor the model to the test data. First, the model was run with the temperatures at TC 1-9 and TC19-TC24 fixed to the test data. The steadystate results were used to calculate a local $h_{\text {eff }}$ for each point on Boundary 2 (note that this is not the boundary condition specified for Boundary 2 in Figure 6). Second, the model was run using a fixed heat flux on Boundary 2, with the heat transfer coefficients determined in the first step, and with fixed temperatures only on Boundary 5 . As expected, the results closely matched the experimental data. Figure 7 illustrates the temperature and velocity 
magnitude contours for the $1-\mathrm{g}$ case anchored to test data. From the numerical perspective, convergence to a steady state was difficult for these calculations. The more accurate solution may be one of unsteady oscillations, as indicated from the experimental evidence for vortex formation and shedding in Figure 5. This possibility, along with other numerical questions, has not been fully addressed, and is beyond the scope of this work.

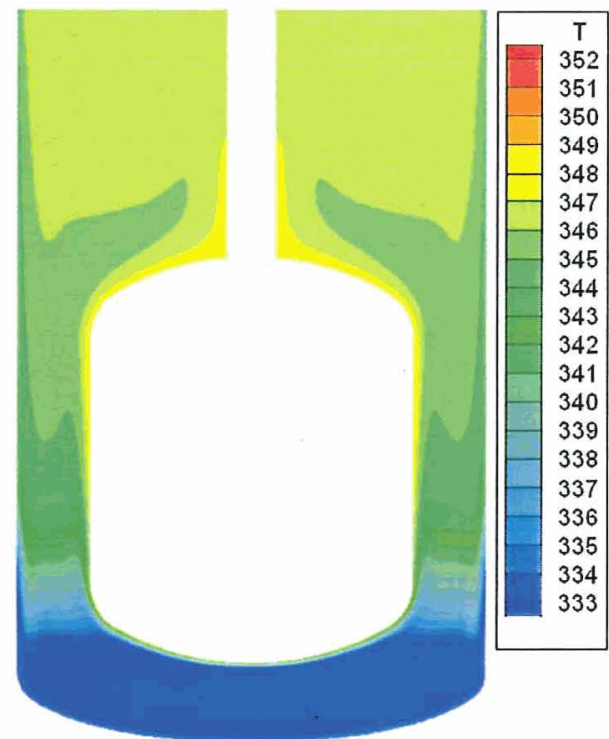

(a) Temperature in Kelvin.

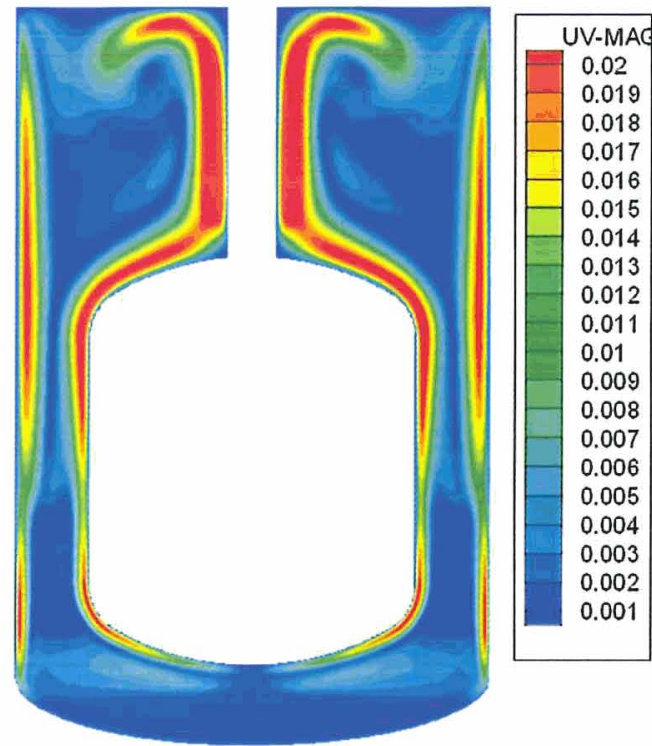

(b) Velocity in Meters per Second.

FIGURE 7. Contours for Axi-Symmetric CFD Model of Water Shield for 1-g case (Anchored to Data).

\section{CFD Model Extrapolated to Lunar Gravity}

Two modifications were made to the CFD model to predict the behavior in lunar gravity. The first is the obvious reduction of the gravitational acceleration. The second is to scale the heat transfer coefficients that were calculated to anchor the model. Aydin and Guessous (2001) provide insight into the scaling of these coefficients, and suggest scaling by gravity to the $1 / 5^{\text {th }}$ power. All other aspects of the $1 / 6$-g case (e.g., boundary conditions, time step, grid spacing, etc.) are identical to the 1 -g case. Figure 8 illustrates the temperature and velocity magnitude contours for the $1 / 6-\mathrm{g}$ case. Note that the scales in Figures 7 and 8 are identical (to aid in comparison) and that this causes the higher temperatures in the 1/6-g and higher velocities in the 1-g case to be 'saturated' on that scale. 


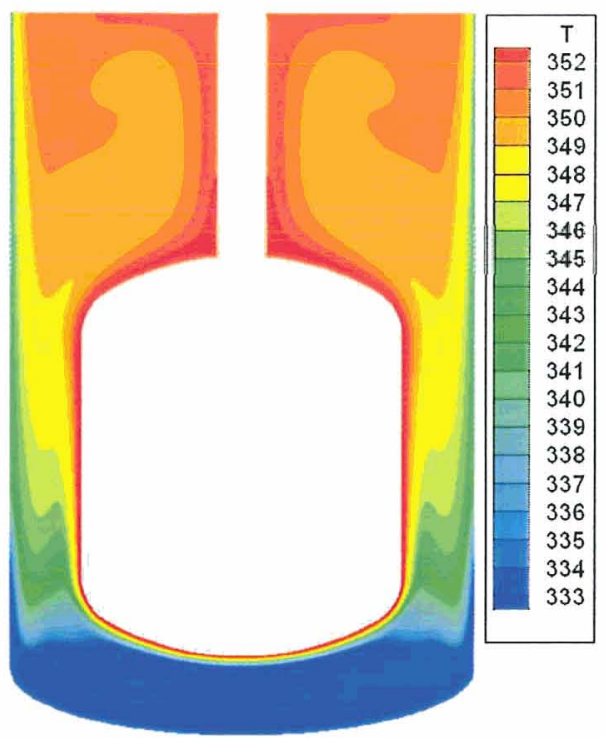

(a) Temperature in Kelvin Absolute.

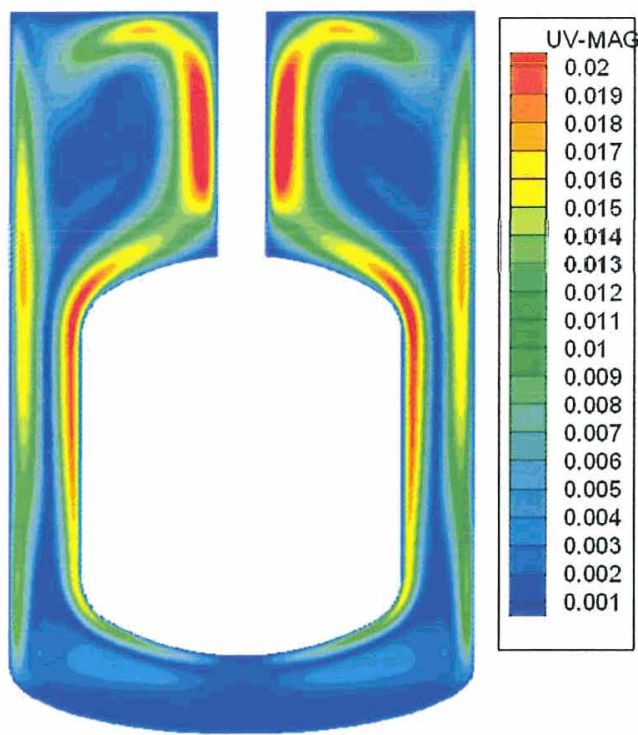

(b) Velocity in Meters per Second.

FIGURE 8. Contours for Axi-Symmetric CFD Model of Water Shield for 1/6-g Case (Lunar Gravity Prediction).

In both cases, the outer boundary condition is a fixed temperature distribution. This is useful in comparison of the effects of gravity on the flow, but obviously provides no insight into the interaction of the water shield with the real boundary condition (most likely radiation to the lunar environment, either directly or through a radiator system).

Overall, velocities are lower and temperatures higher in the lunar case, as expected. But the bouyancy forces in the lunar case are still strong enough to drive a significant circulation of the water, and provide heat transfer through the water shield. Because the boundary condition on the core is a fixed heat flux, the same amount of heat is moved through the shield in both cases. For this heat load, the reduced flow and convective heat transfer drive the core simulator temperatures up to $16^{\circ} \mathrm{C}$ higher in the lunar case. Specific temperatures at the thermocouple locations on the core simulatore for both cases are tabulated in Table 1. While this increase in temperature is significant, it does not significantly affect the design of the shield as a pressure vessel.

Table 1. CFD Predicted Temperatures for $1-\mathrm{g}$ (anchored) and 1/6-g (predicted) cases at the WST thermocouple locations.

\begin{tabular}{ccc}
\hline TC \# & $\begin{array}{c}\text { 1-g, anchored } \\
\mathbf{T}\left({ }^{\circ} \mathbf{C}\right)\end{array}$ & $\begin{array}{c}\text { 1/6-g, predicted } \\
\text { T }\left({ }^{\circ} \mathbf{C}\right)\end{array}$ \\
\hline 1 & 74.5 & 79.8 \\
\hline 2 & 74.8 & 80.5 \\
\hline 3 & 74.5 & 80.0 \\
\hline 4 & 75.1 & 81.4 \\
\hline 5 & 74.4 & 81.0 \\
\hline 6 & 73.8 & 82.4 \\
\hline 7 & 72.5 & 83.6 \\
\hline 8 & 72.4 & 88.2 \\
\hline 9 & 69.7 & 84.6 \\
\hline 10 & 73.8 & 78.5 \\
\hline
\end{tabular}

This analysis provides a good first look at a correlation between ground testing (in a 1-g environment) and prediction of natural convection in $1 / 6-\mathrm{g}$. Several steps can be taken to increase the fidelity of the correlation and the numerical predictions. ${ }^{* * *}$ Eric, could you put in numerical/CFD suggestion?*** A fluid temperature rake 
and/or flow visualization could be added to the experimental setup to help anchor conditions throughout the water, rather than just at the boundaries.

\section{SUMMARY}

Adequate shielding is critical to any surface power reactor system. To date, water has not typically been considered for the shielding of space reactor systems because of temperature requirements associated with thermoelectric and thermionic power conversion. Water based shields become very attractive at the lower temperatures now being contemplated for lunar nuclear power systems. Water shields offer potential advantages, including reduced cost, reduced technical risk, and reduced mass. This work shows an early experimental demonstration of the water shield concept, specifically targeted to answer key thermal management questions. The experiment was conducted at $1-\mathrm{g}$ with full-scale prototypic geometry and heat load. Water temperatures in this experiment reached a maximum of 75 ${ }^{\circ} \mathrm{C}$. This experimental data was used to anchor a CFD model of the WST. The CFD model was then used to predict the thermal performance in lunar gravity. Predictions showed that the natural convection, while reduced, was still sufficient to keep water temperatures to a maximum of $88^{\circ} \mathrm{C}$. This difference between $1-\mathrm{g}$ and $1 / 6-\mathrm{g}$ performance would not significantly affect the shield design, and supports the usefulness and validity of using a $1-\mathrm{g}$ testbed to evaluate designs to be used in a lunar environment.

\section{ACKNOWLEDGMENTS}

The authors wish to recognize the contributions of the following members of the Marshall Space Flight Center EFFTF team: Kenny Webster, Roger Harper, Gene Fant, Jason Berry, and Stan MacDonald. This work was funded by NASA through the Prometheus Program in support of the Vision for Space Exploration.

\section{REFERENCES}

Angelo, J.A. and Buden, D., Space Nuclear Power, Orbit Book Co., Malabar, FL, 1985, pp. 133-157.

Aydin, O., and Guessous, L., "Fundamental Correlations for Laminar and Turbulenct Free Convection from a Uniformly Heated Vertical Plate," International Journal of Heat and Mass Transfer, 44 (2001) 4605-4611.

Baldwin, B.S., and Lomax, H., "Thin Layer Approximation and Algebraic Model for Separated Turbulent Flows," AlAA-78-257, AIAA $16^{\text {th }}$ Aerospace Sciences Meeting, Huntsville, Alabama, January 16-18, 1978.

Bragg-Sitton, S.M., "Heat Pipe Reactor Dynamic Response Tests: SAFE-100a Reactor Core Prototype," in proceedings of the Space Nuclear Conference (SNC-2005) American Nuclear Society, San Diego, CA, 2005, p. 781-789.

Dixon, D., Hiatt, M., Poston, D. and Kapernick, R., "Design of a 25-kWe Surface Reactor System Based on SNAP Reactor Technologies," in proceedings of Space Technology and Applications International Forum (STAIF-2006), edited by M.S. El-Genk, AIP Conference Proceedings 813, AIP, New York, 2006, pp. 932-941.

Godfroy T., et al., "Thermally Simulated Direct-Drive Gas-Cooled Reactor for Near Term Space Fission Systems," in proceedings of Space Technology and Applications International Forum (STAIF-2004), edited by M.S. El-Genk, AIP Conference Proceedings 699, AIP, New York, 2004, pp. 757-763.

Qualls, L., et al., Overview "PRESTO: Power Reactor for Surface Terminal Operation", Proceedings of the Space Nuclear Conference-2005, San Diego -CA, June 5-9, 2005, Paper 1082, pp. 497-506.

Stewart, E., "Natural Convection Analyses in Support of the Transient Dendritic Solidification Experiment (TDSE)," Memorandum ED25-01-01, NASA Marshall Space Flight Center, Huntsville, AL, September 12, 2001.

Tecplot User's Manual Version 8.0, Amtec Engineering, Inc., Bellevue, Washington, 1999.

Wagner, D., Radiosotopic-Fueled General Purpose Heat Source (GPHS) Simulator for use in Surface Power System Development", Internal Research and Development (MSFC-IRAD), NASA Marshall Space Flight Center, Huntsville, AL, 2004. 


\title{
Experimental Evaluation of the Thermal Performance of a Water Shield for a Surface Power Reactor
}

\author{
J Boise Pearson, \\ Eric T. Stewart \\ NASA Marshall Space Flight Center \\ Robert S. Reid \\ Los Alamos National Laboratory \\ STAIF 2007 \\ 12 February, 2007
}




\section{FFissfion Sufface Poower}

\section{Acknowledgements}

The authors wish to recognize the contributions of the following members of the Marshall Space Flight Center EFFTF team: Kenny Webster, Roger Harper, Gene Fant, Jason Berry and Stan MacDonald.

This work is funded by NASA through the Prometheus Program in support of the Vision for Space Exploration. 
The case for a water shield for Lunar surface reactors

-Water is a great neutron shield

- No materials R\&D program necessary

- No cracks or voids

The Water Shield Testbed

- Geometry representative of the LANL SNAP-derivative design concept (100 kWt, $25 \mathrm{kWe})$

- Max heat input into core simulator of $18 \mathrm{~kW}$

- Primary instrumentation is thermocouples

- Testbed results are used to anchor CFD models 


\section{FFisssion Surface Powerer}

Testbed Configuration

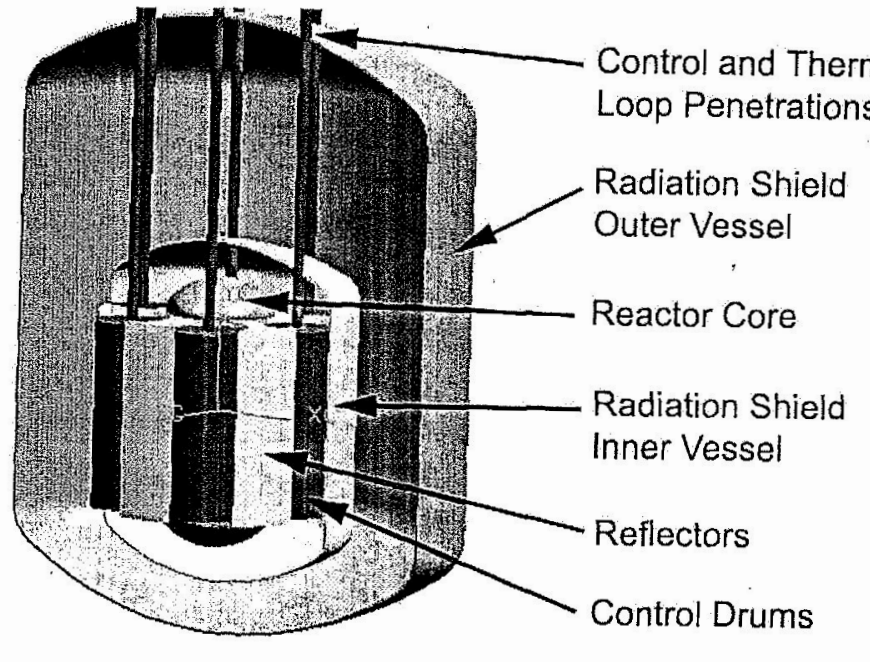

LANL water shield concept

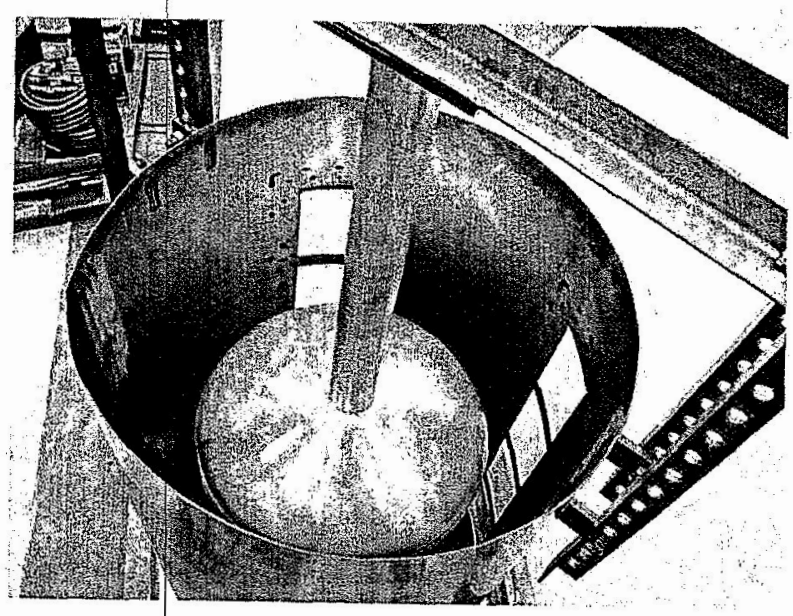

Core simulator in outer tank

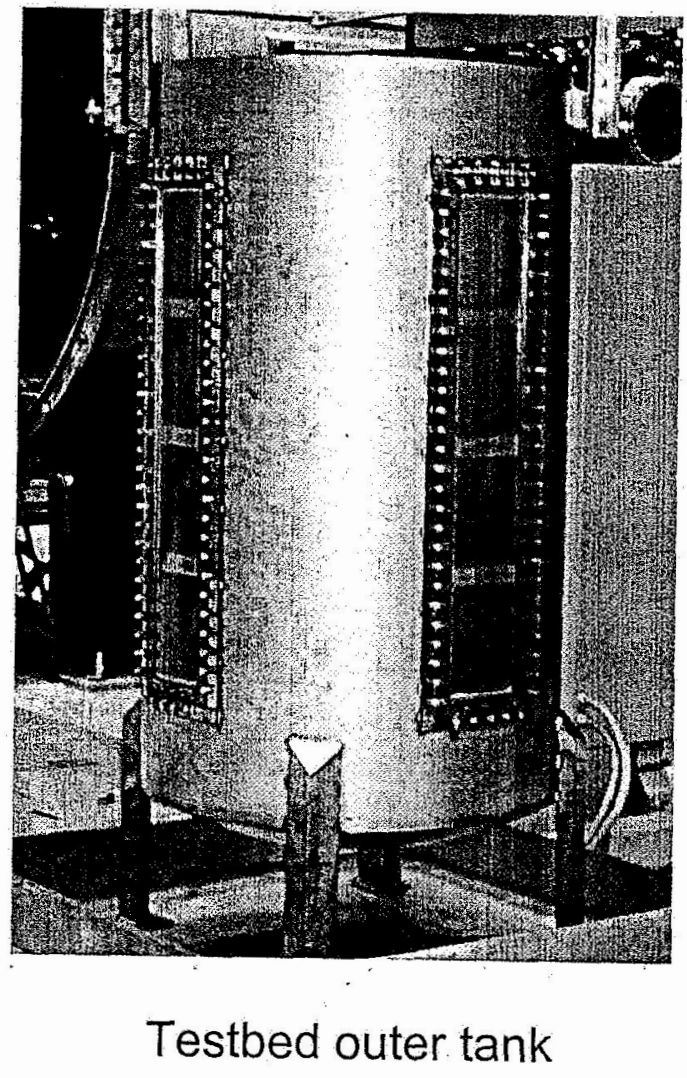

Testbed outer tank 


\section{FFisspion Surface Popwer}

Core Heater Placement and Instrumentation

One thermocouple in each

heater zone. Placed

between heaters and wall

to monitor heater temps
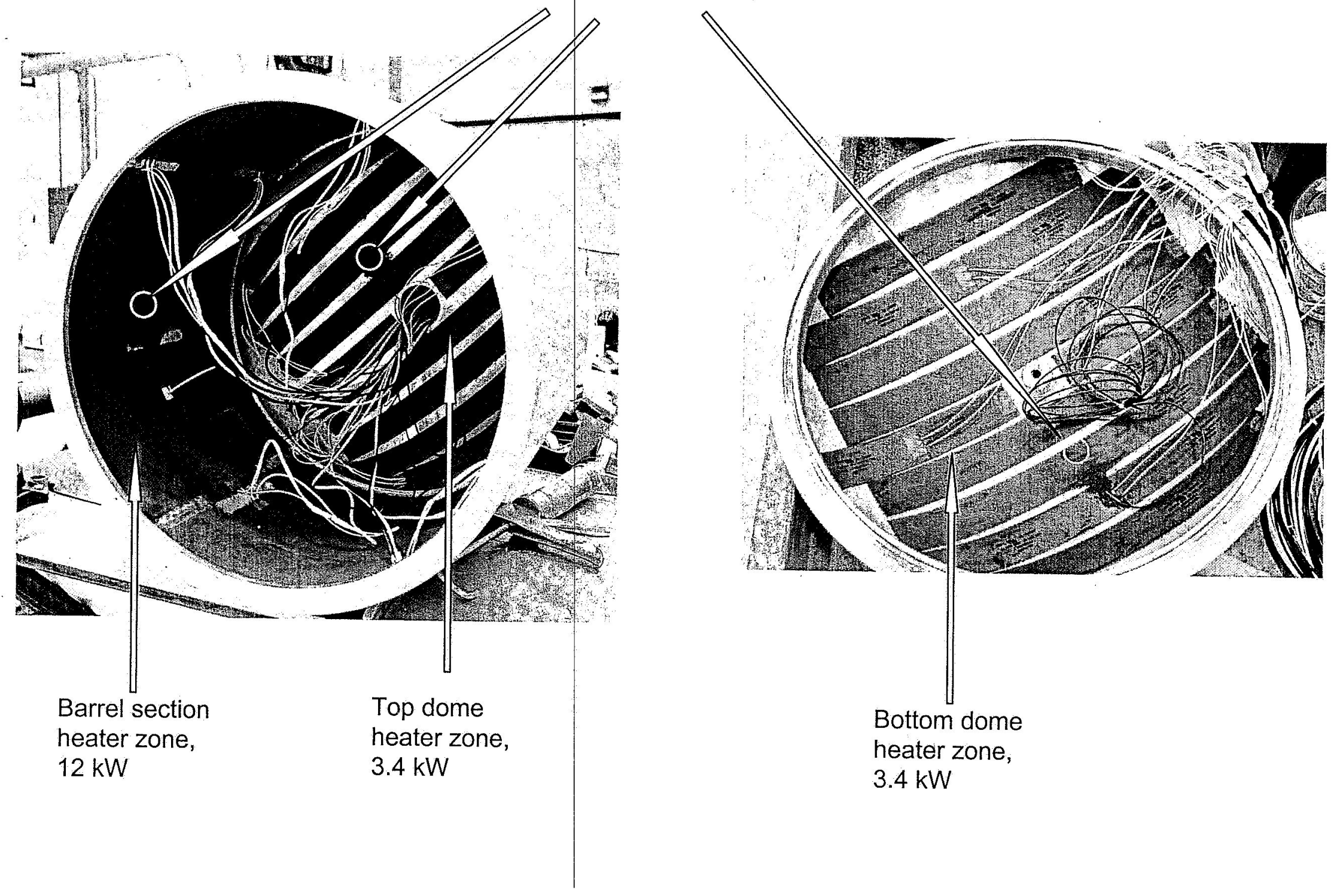

Bottom dome

heater zone,

$3.4 \mathrm{~kW}$ 


\section{Fisission Surface Power}

Thermocouple Placement

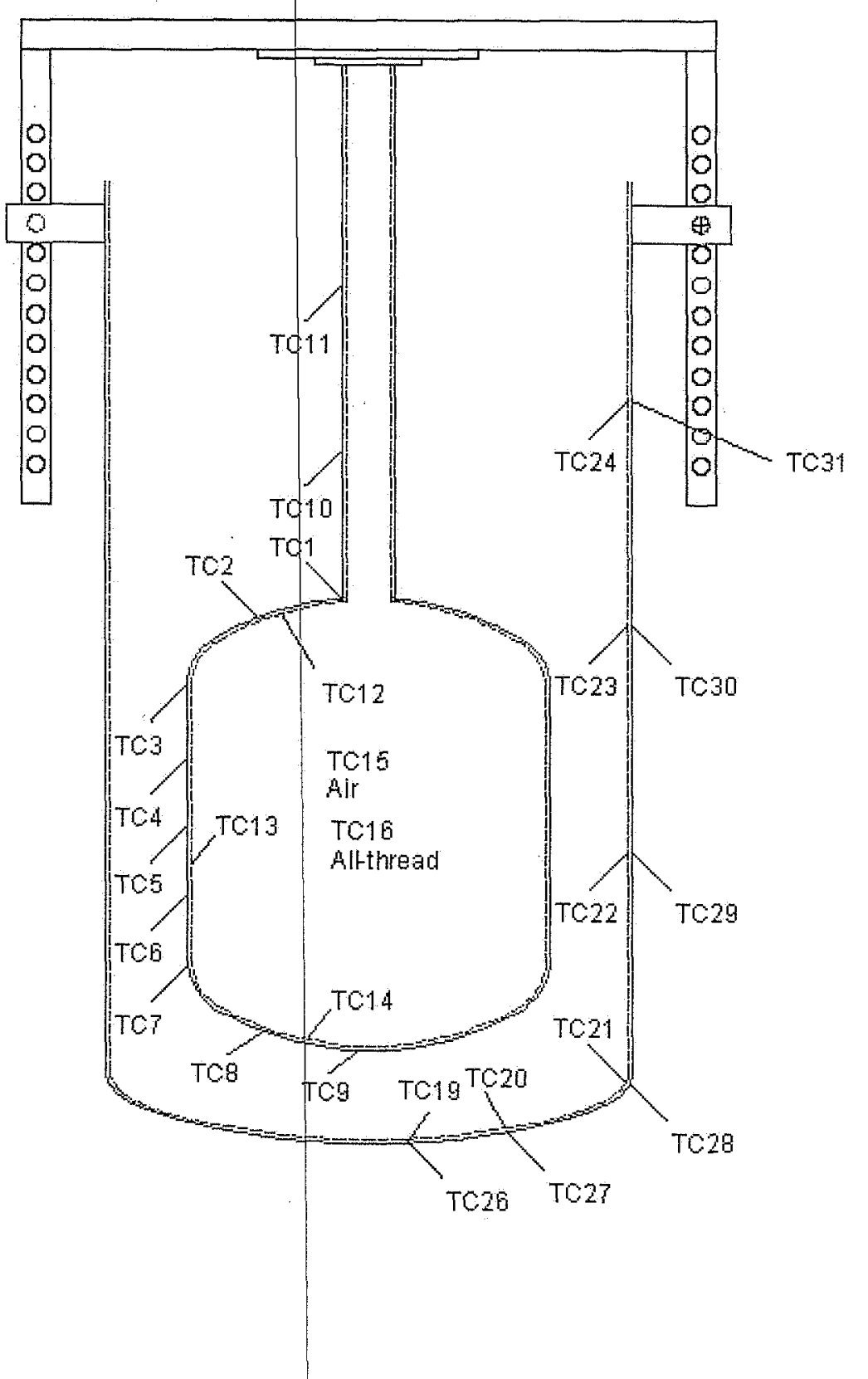




\section{Fisission Sufface Ppower}

Core Thermocouple Placement

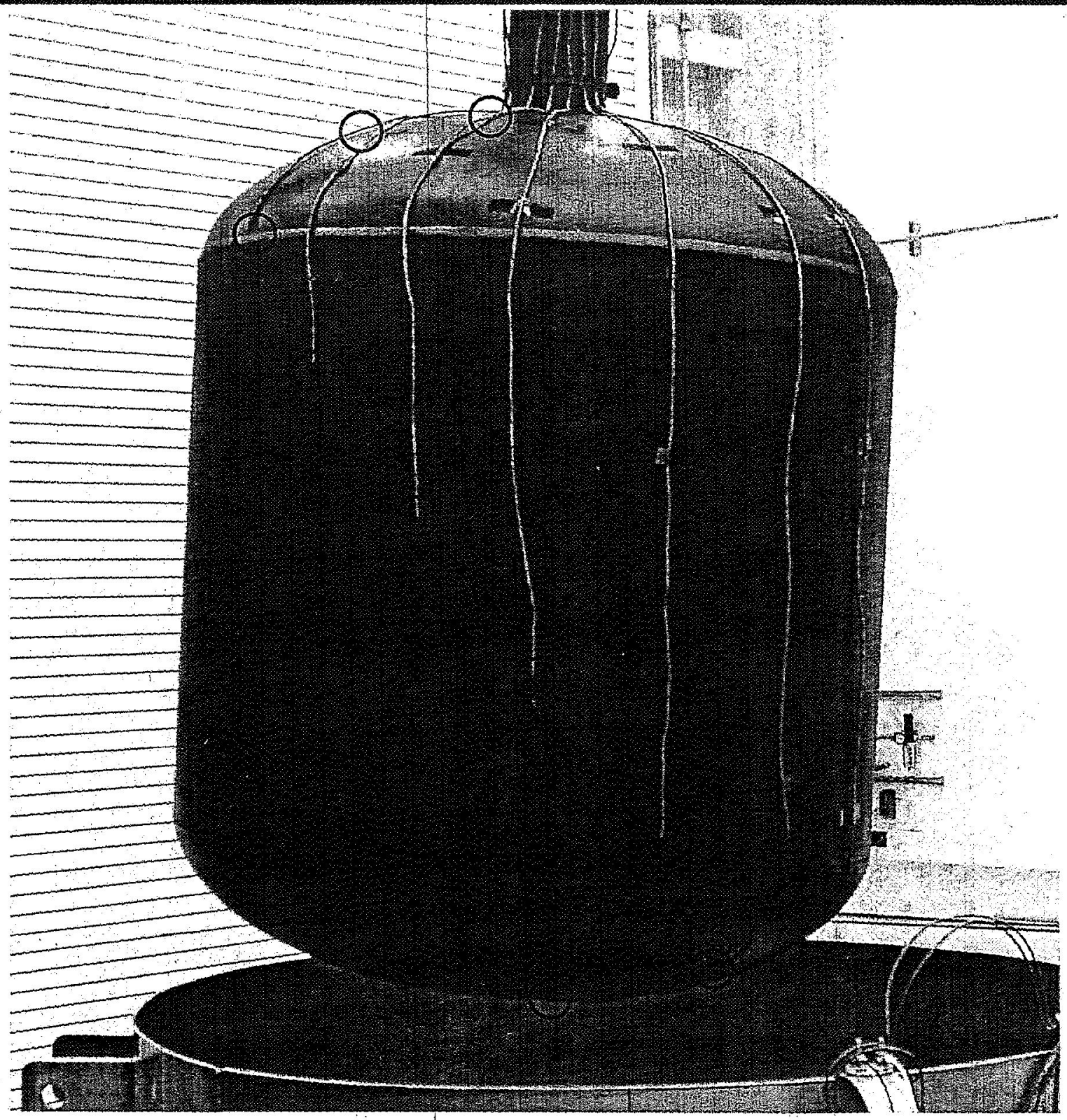




\section{Fisispion Surface Powerer}

\section{Outer Tank Thermocouple Placement}

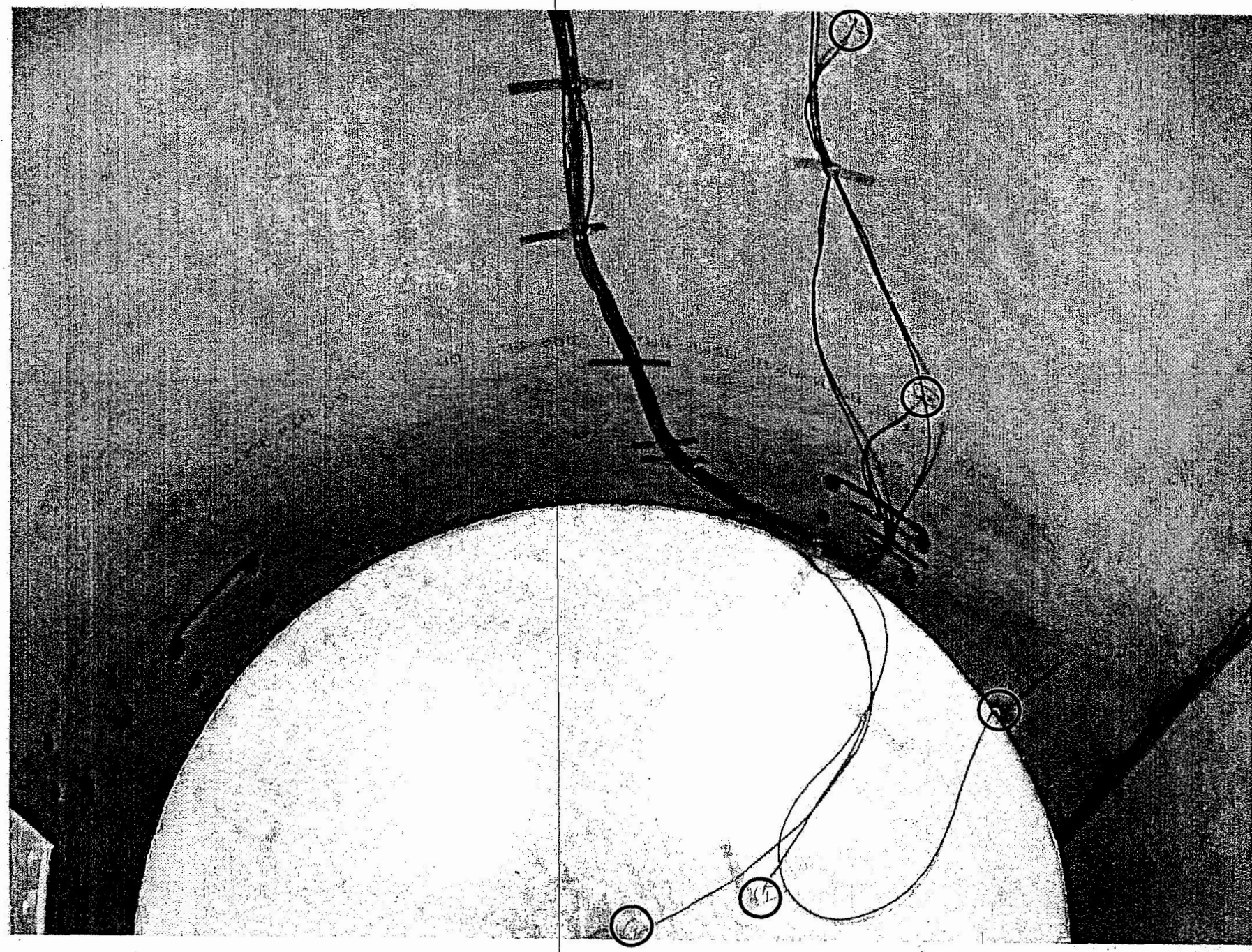




\section{Fiśssion Sufface Powwer}

Integrated Testbed

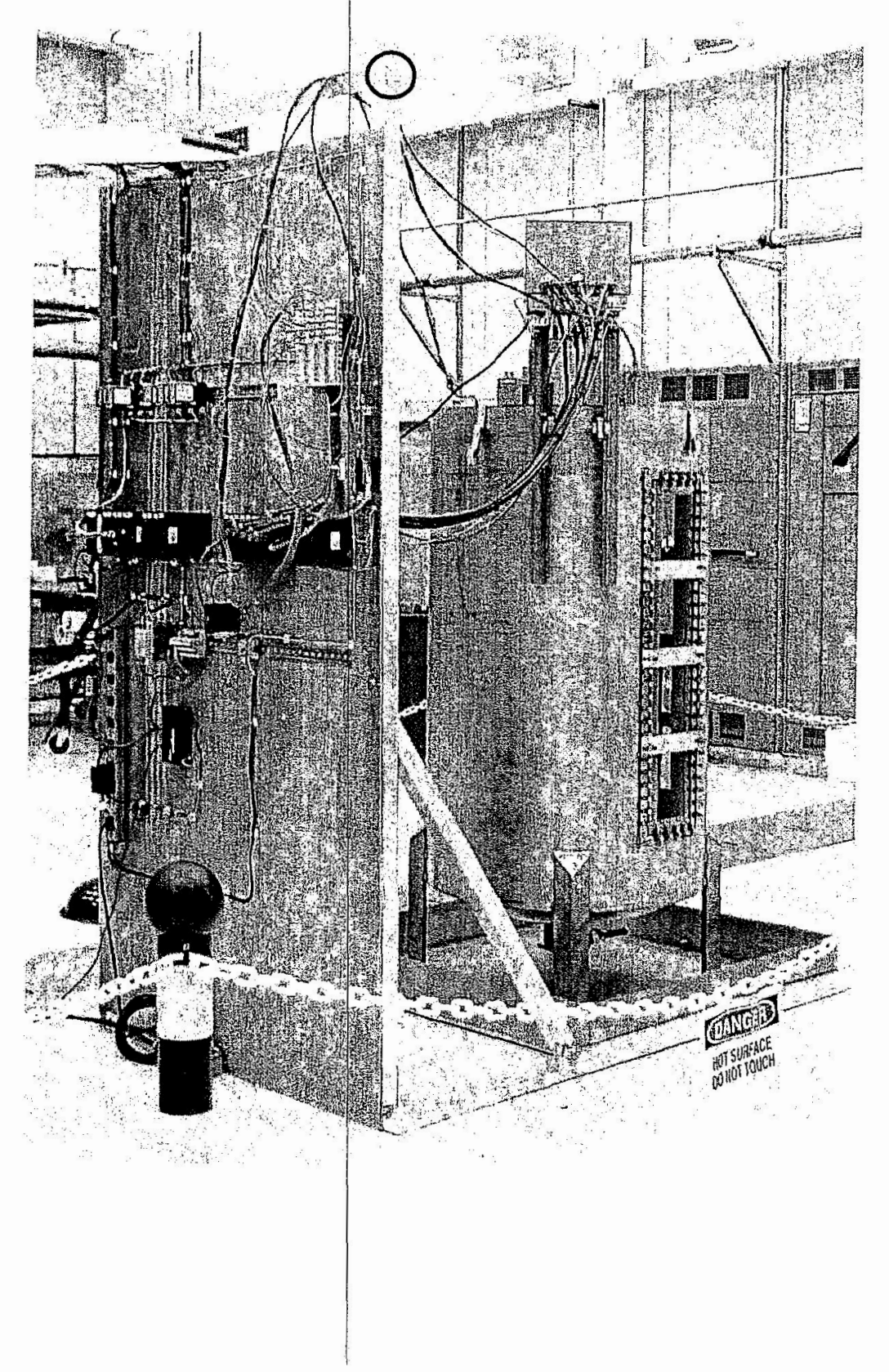




\section{Fisssoion Surface Powerer}

\section{Methodology}

- The Water Shield Testbed was run using $2 \mathrm{~kW}$ thermal power to develop a steady-state temperature profile

- A steady-state CFD model was anchored to the 2-kW test data

- The CFD model was then used to model the same experiment in $1 / 6-g$ 


\section{Fisission Sufface Power}

Experimental Results: Core Temperatures

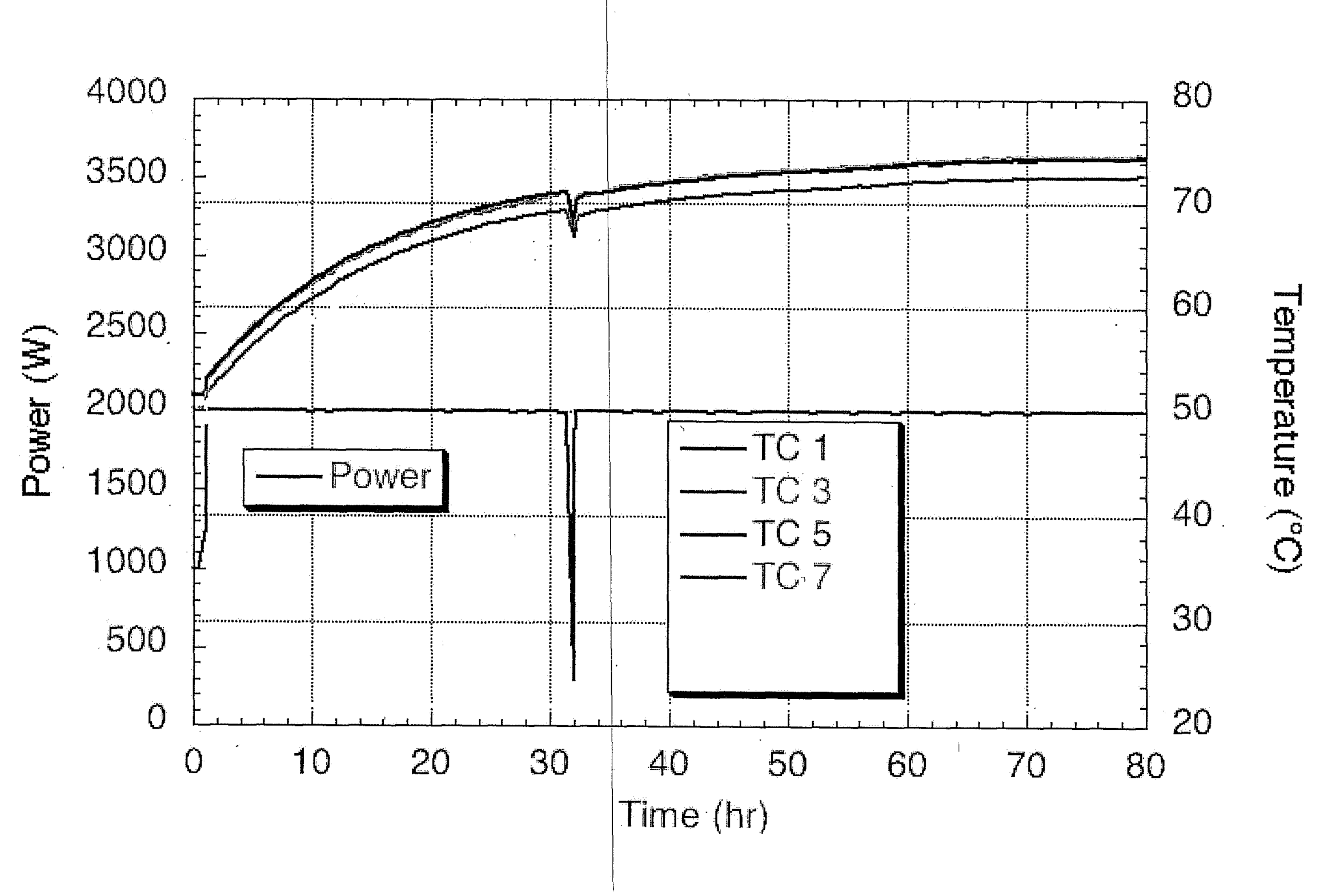




\section{Fisisspion Surface Powerer}

Experimental Results: Outer Tank Temperatures

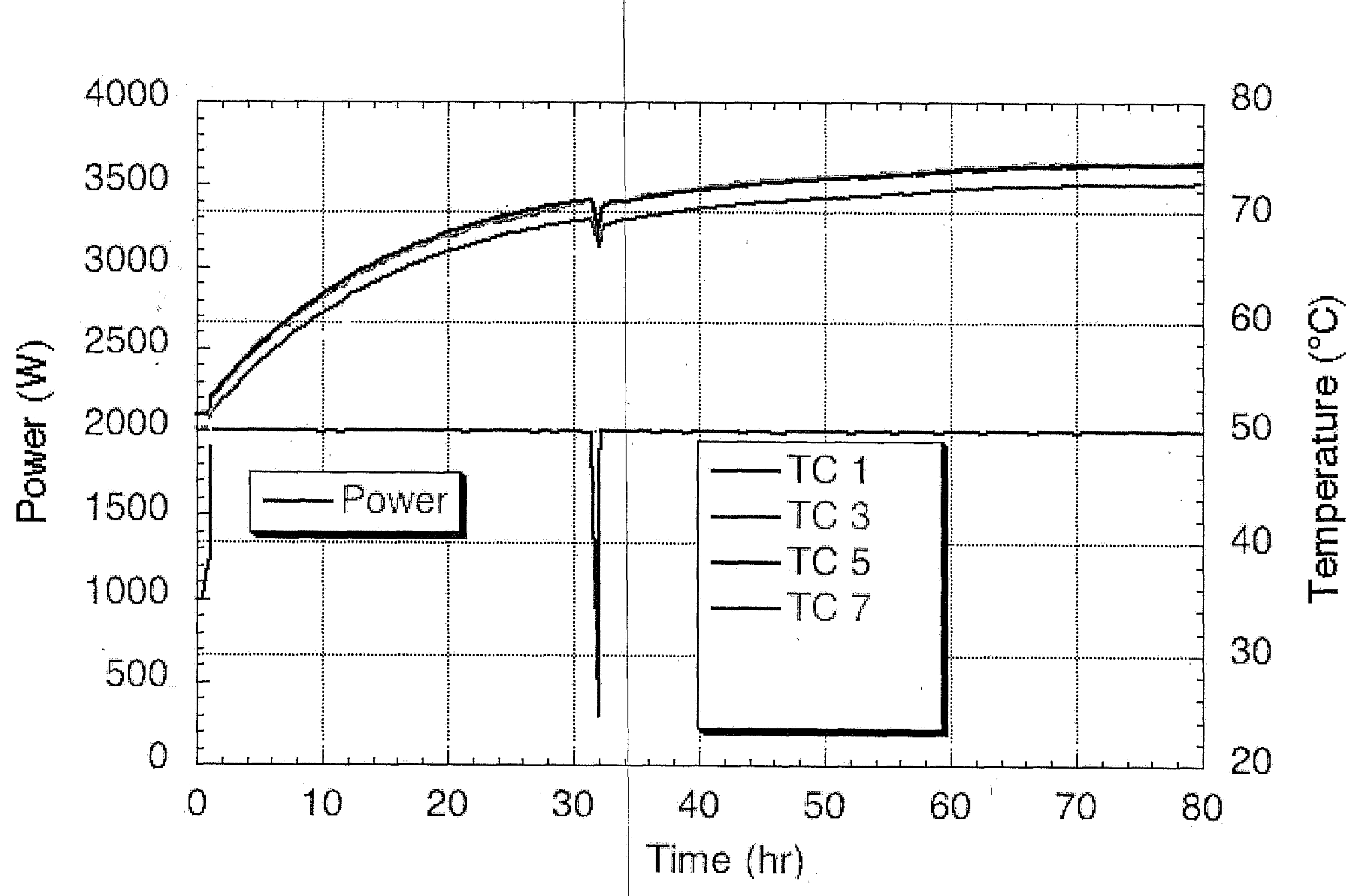




\section{FFissfion Surface Powerer}

\section{CFD Modeling}

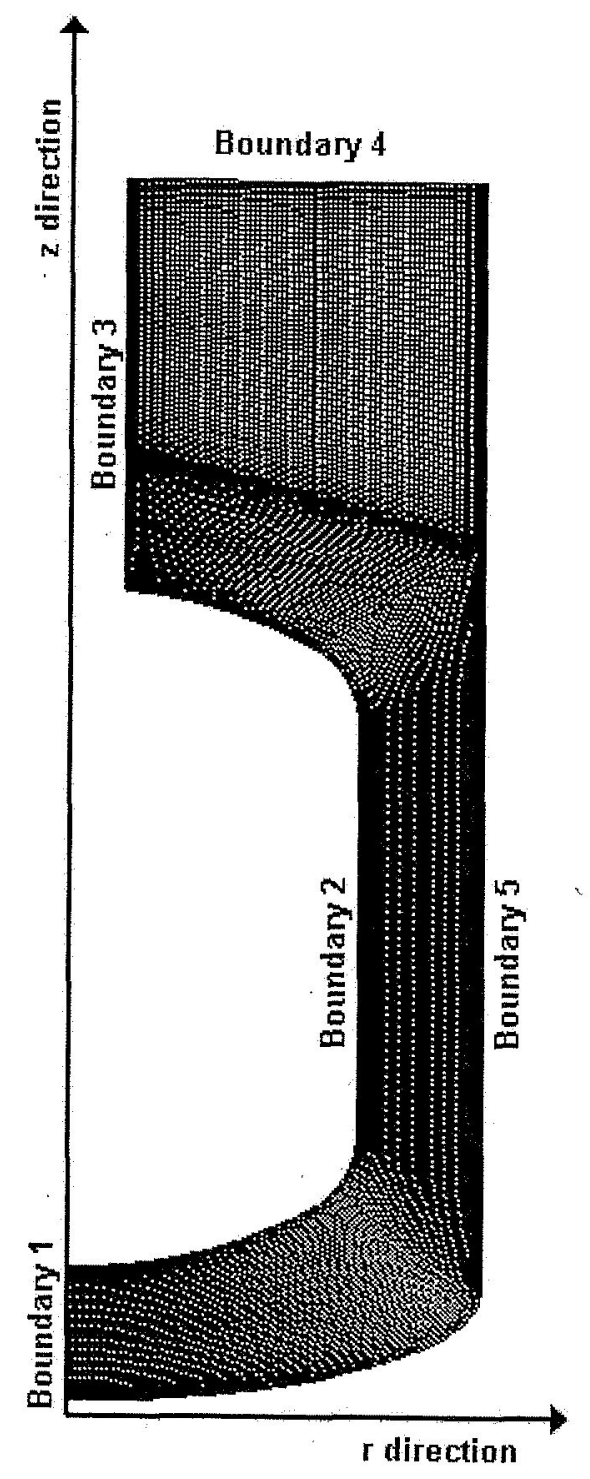

Boundary 1

$$
u_{r}^{*}=0, \frac{\partial u_{z}^{*}}{\partial r^{*}}=\frac{\partial T^{*}}{\partial r^{*}}=\frac{\partial P^{*}}{\partial r^{*}}=0
$$

Boundary 2

$$
\boldsymbol{u}_{r}^{*}=\boldsymbol{u}_{z}^{*}=0, \frac{\partial T^{*}}{\partial n^{*}}=\frac{q^{*}}{h_{e f f}^{*}}, \frac{\partial P^{*}}{\partial n^{*}}=0
$$

Boundary 3

$$
u_{r}^{*}=\boldsymbol{u}_{z}^{*}=0, \frac{\partial T^{*}}{\partial r^{*}}=\frac{\partial P^{*}}{\partial r^{*}}=0,
$$

Boundary 4

$$
u_{r}^{*}=\boldsymbol{u}_{z}^{*}=0, \frac{\partial T^{*}}{\partial z^{*}}=\frac{\partial P^{*}}{\partial z^{*}}=0,
$$

Boundary 5

$$
u_{r}^{*}=u_{\varepsilon}^{*}=0, T^{*}=T_{\text {exp }}^{*}, \quad \frac{\partial P^{*}}{\partial n^{*}}=0,
$$




\section{FFisspion Surface Powerer}

CFD Model: Anchored to Experimental Results (1-g)
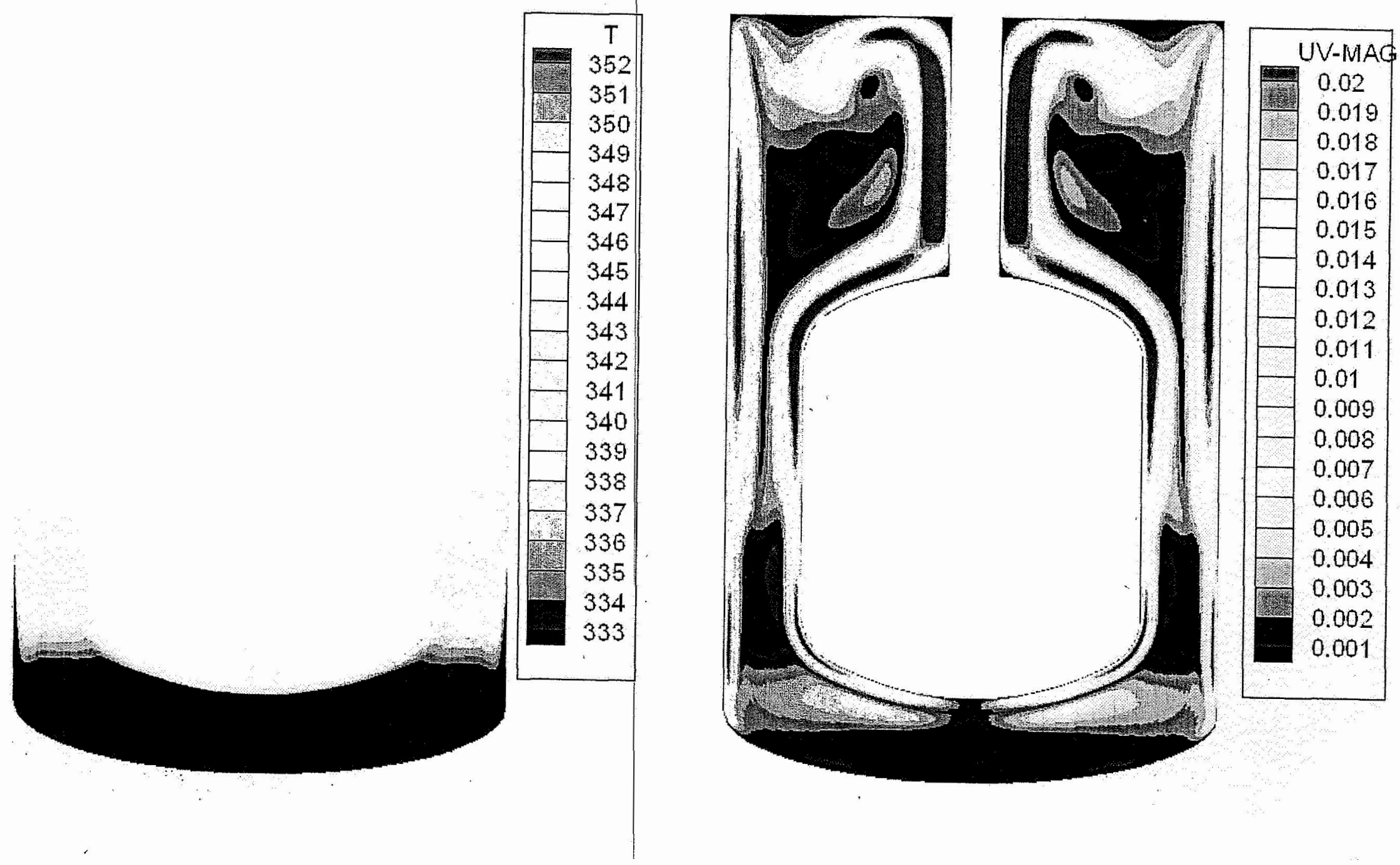


\section{Fisission Surface Powerer}

CFD Model: Prediction for $1 / 6-\mathrm{g}$
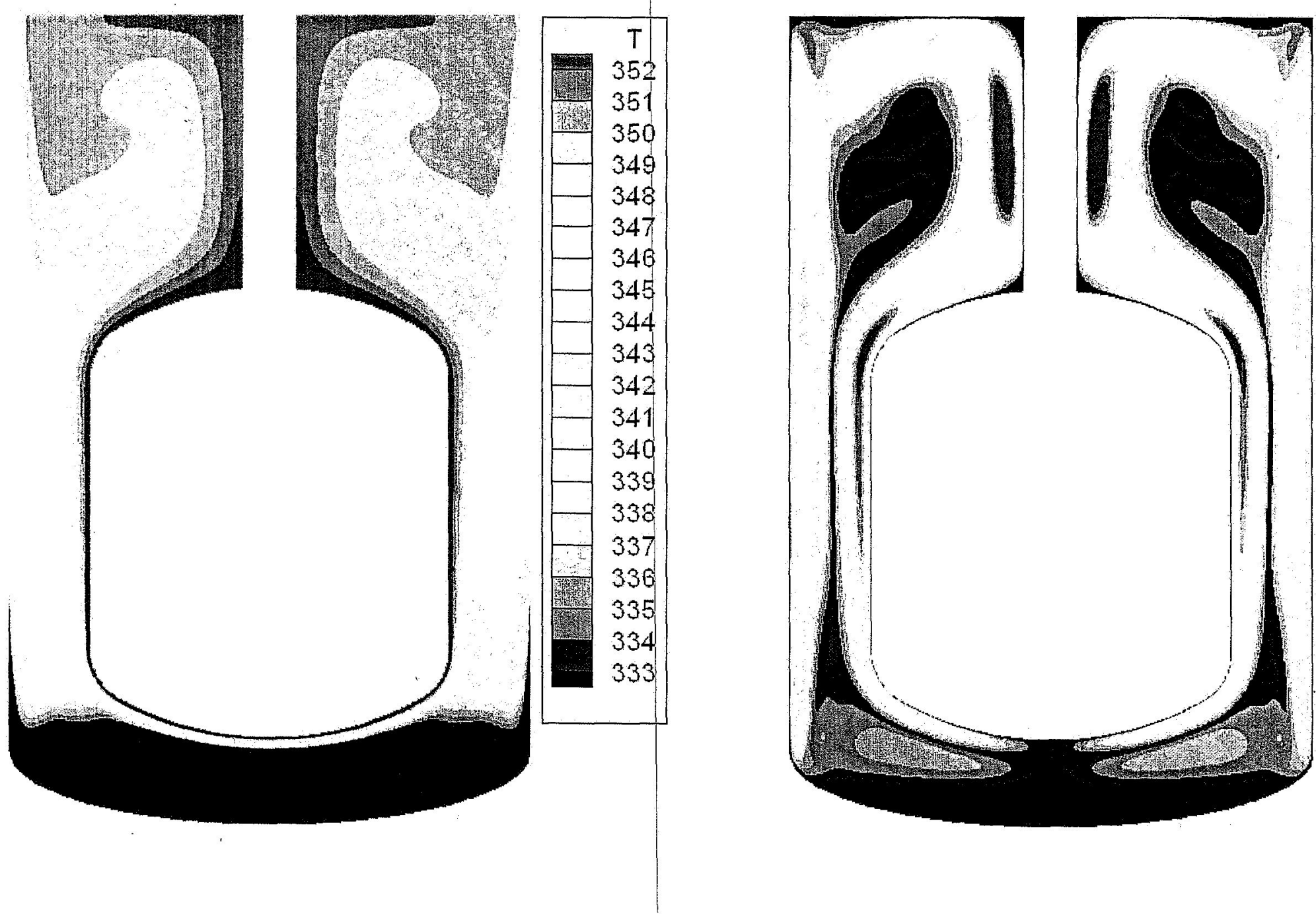

UV-MAG

0.02

0.019

0.018

0.017

0.016

0.015

0.014

0.013

0.012

0.011

0.01

0.009

0.008

0.007

0.006

0.005

0.004

0.003

0.002

0.001 


\section{Fisission Surface Powerer}

CFD Model: Comparison of $1-\mathrm{g}$ to $1 / 6-\mathrm{g}$

\begin{tabular}{|c|c|c|}
\hline TC \# & $\begin{array}{c}\mathbf{1 - g}, \mathbf{a n c h o r e d} \\
\mathbf{T}\left({ }^{\circ} \mathbf{C}\right)\end{array}$ & $\begin{array}{c}\mathbf{1 / 6 - g}, \text { predicted } \\
\mathbf{T}\left({ }^{\circ} \mathbf{C}\right)\end{array}$ \\
\hline 1 & 74.5 & 79.8 \\
\hline 2 & 74.8 & 80.5 \\
\hline 3 & 74.5 & 80.0 \\
\hline 4 & 75.1 & 81.4 \\
\hline 5 & 74.4 & 81.0 \\
\hline 6 & 73.8 & 82.4 \\
\hline 7 & 72.5 & 83.6 \\
\hline 8 & 72.4 & 88.2 \\
\hline 9 & 69.7 & 84.6 \\
\hline 10 & 73.8 & 78.5 \\
\hline
\end{tabular}




\section{FFisşion Sufface Poower}

\section{Summary and Conclusions}

- The experiment was conducted at 1 -g with full-scale prototypic geometry and heat load $(2 \mathrm{~kW})$. Water temperatures in this experiment reached a maximum of $75^{\circ} \mathrm{C}$.

- The experimental data was used to anchor a CFD model of the WST. The CFD model was then used to predict the thermal performance in lunar gravity.

- Predictions showed that the natural convection, while reduced, was still sufficient to keep water temperatures to a maximum of $88^{\circ} \mathrm{C}$.

- This predicted difference between $1-\mathrm{g}$ and $1 / 6 \mathrm{~g}$ performance would not greatly affect the shield design, and supports the usefulness and validity of using a $1-\mathrm{g}$ test bed to evaluate designs to be used in a lunar environment.

- Possible Future Direction

- Qualitative flow visualization

- Heat pipes and heat exchanger for higher power heat removal

- Modified core geometries

- Integration of water shield into a surface power reactor system demonstration at the EFF-TF 


\section{Fisissfion Sufface Powerer}

Periodic Oscillations in Flow

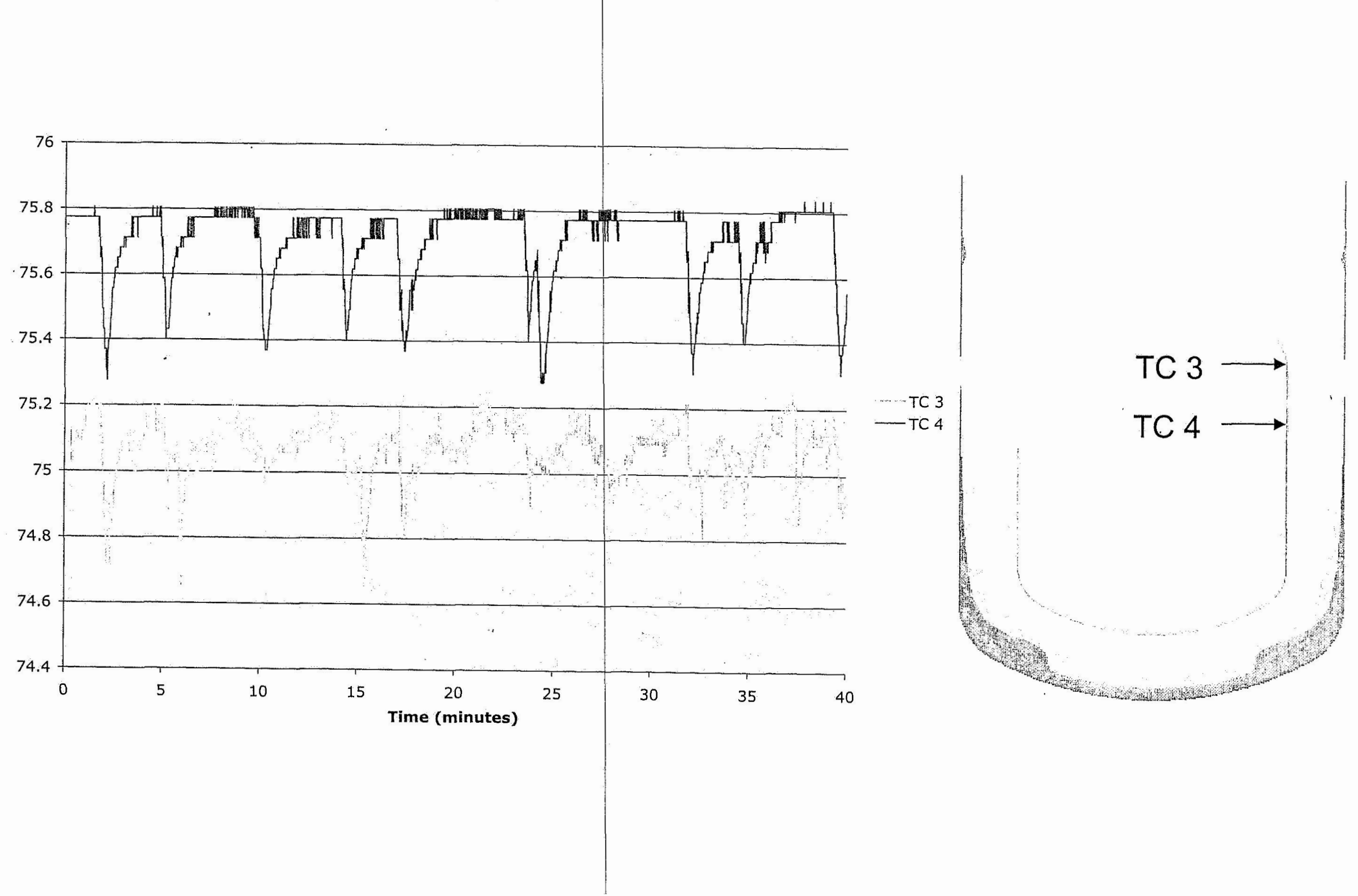

